\title{
Distribution of HCHs and DDTs in Soils from Beijing City, China
}

\author{
Xinghong Li, ${ }^{1}$ Youfeng Zhu, ${ }^{1}$ Xiufen Liu, ${ }^{1}$ Shan Fu, ${ }^{1}$ Xiaobai Xu, ${ }^{1}$ Hangxin Cheng ${ }^{2}$ \\ ${ }^{1}$ State Key Labotory of Environmental Chemistry and Ecotoxicology, Research Center for Eco-Environmental Sciences, Chinese Academy of Sciences, \\ P.O. Box 2871, Beijing 100085, China \\ ${ }^{2}$ Institute of Geophysical and Geochemical Exploration, Langfang 065000, China
}

Received: 14 March 2005/Accepted: 4 December 2005

\begin{abstract}
Concentrations of $\mathrm{HCH}$ isomers, DDT, and its metabolites have been measured in 63 soil samples collected in the urban area and outskirts of Beijing City. HCHs and DDTs were observed in all samples and their geometric mean levels were 5.78 and $38.21 \mathrm{ng} \mathrm{g}^{-1}$, respectively. The spatial distribution of OCPs in Beijing was clearly showed by the contour map, suggesting the sites with the higher level of OCPs are located in the west and the south region and urban areas within the study regions." Furthermore, a $t$-test showed a significant difference of the level of some compounds between urban and outskirts areas. The temporal distribution of HCHs and DDTs suggested that the historical application of OCPs has a great effect on the residual level. The ratios of $(\alpha-/ \gamma-\mathrm{HCH}(\mathrm{p}, \mathrm{p}-$ DDE+p,p'-DDD)/p,p'-DDT, and o,p'-DDT/p,p'-DDT indicated the present of lindane and impure dicofol besides technical $\mathrm{HCH}$ and technical DDTs in Beijing. The potential risk of $\mathrm{HCHs}$ and DDTs was assessed on the basis of some current guideline values for soil. The level of OCPs in our study area was compared with other studies.
\end{abstract}

Hexachlorocyclohexane $(\mathrm{HCH})$ was widely used as an insecticide on fruits and vegetables, rice paddies, trees, and animals and as a seed treatment in the middle of the last century (Haugen et al. 1998). It also has been applied topically to people for the treatment of parasites. Dichlorodiphenyltrichloroethane (DDT) has been used worldwide as an active insecticide in agriculture, both for pest control and for vector control in human hygiene against diseases such as malaria and typhus since the 1940s (Kannan et al. 1995). Due to the high toxicity and persistence of both HCHs and DDTs, their bioaccumulation to non-target organisms in the ecosystem has been of great environmental concern (Jones et al. 1999). In China, Organochlorine pesticides (mainly DDTs and $\mathrm{HCHs}$ ) used to be the most important pesticides, produced to enhance agricultural yields, forestry, and public health for more than three decades (Cai et al. 1992; Li et al. 1998). A

Correspondence to: Xiaobai Xu; email: xuxb@public.bta.net.cn national survey in the 1980s showed the amount of OCPs occupied about $78 \%$ of all pesticide consumption during that period. Though the Chinese government banned the usage of technical HCHs and DDTs in 1983, lindane (about 99\% $\gamma-\mathrm{HCH}$ ) is still allowable to use in a restricted way (Li et al. 2001) and DDT is officially restricted to campaigns for vector control or as the intermediate of dicofol nowadays. After decades banned, DDTs still can be found in the environment due to their persistence ( $\mathrm{Li}$ et al. 1998; Zhao and Ma 2001).Beijing is one of the biggest cities in northern China, as the capital with a population of $13,819,000$. The city area occupies a surface of $16,807 \mathrm{~km}^{2}$, with $750 \mathrm{~km}^{2}$ classed as urban areas. The climate of the country as a whole is dominated by temperate semi-wetness monsoons, with daily average temperatures ranging from $10-27^{\circ} \mathrm{C}$. The hypsography of Beijing is higher in the northwest direction than that in the southeast direction so that the wind blows and river flows from the northwest to east-south area. From the 1960s to the 1980s, large amounts of DDTs and HCHs were applied in the areas of Beijing for agricultural yield and/or sanitation (Cai et al. 1992; Li et al. 1998). In addition, waste water has commonly been used to irrigate the soil because of the shortage of water in the Beijing area. As a result, the history of pollution in the area is long and the sources of various contaminants complex. Recently, some studies revealed that the atmosphere in the urban area of Beijing still contained HCHs and DDTs with high levels (Wu et al. 2003; Xu et al. 2004, 2005). Zhang et al. (2004) reported that the water in the Tonghui River, which is a main urban drainage river for Beijing, was moderately polluted by organochlorine pesticides. Generally, the soil was considered as the ultimate sink for OCPs ( Fu et al. 2003). OCPs in soil can enter into the atmosphere by evaporation and migrate into water by rain, thus causing direct or indirect exposure of humans to the organic pollutants (Finizion et al. 1998; Waite et al. 1995). However, related work was done only 20 years ago and the current polluted situation in the region was not well known. These factors push us to monitor these pollutants.

The main objective of the present study was to investigate the residue levels of HCHs and DDTs, and to identify possible differences in the spatial distribution and composition characteristics of OCPs, and to assess the previous and current possible inputs of the OCPs pollutants in the surface soils 


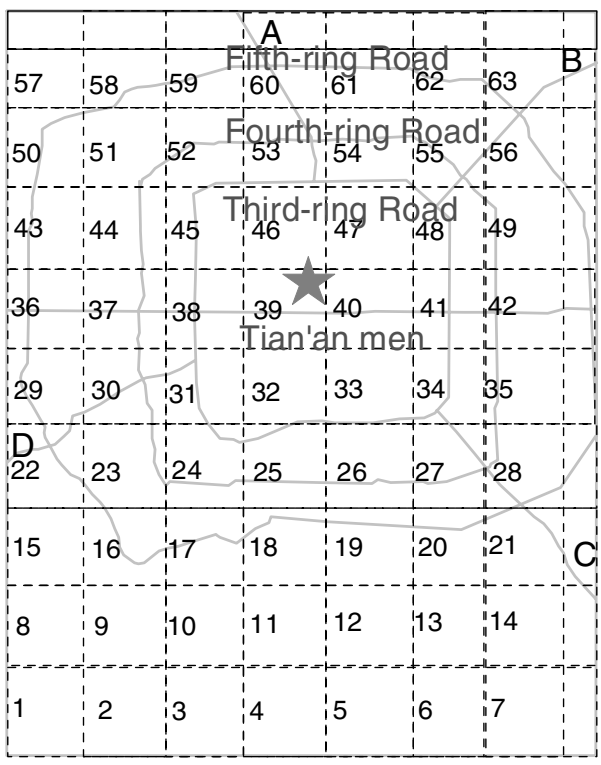

A:Badaling Highway B:Shoudujichang Highway

C: Beijing_Tanggu Highway D: Beijing_Shijiazhuang Highway

Fig. 1. Geographic location of samples sites

collected from the Beijing area. The information will be useful for improving our understanding of the sources and current contamination status of OCPs in the area.

\section{Materials and Methods}

\section{Reagents and Standards}

Stock solutions of eight organochlorine pesticides including $\alpha-\mathrm{HCH}$, $\beta-\mathrm{HCH}, \gamma-\mathrm{HCH}, \delta$-HCH, p,p'-DDT, p,p'-DDE, p,p'-DDD, and o, $p^{\prime}-$ DDT were obtained from National Research Center for Certified Reference Materials of China at a concentration of $100 \mathrm{mg} \mathrm{L}^{-1}$ and further diluted to obtain the desired concentration. 2,4,5,6-tetrachloro$m$-xylene (TCMX) from Supelco (Bellefonte, PA) was used as surrogates. All solvents were of analytical purity (Beijing Chemical Factory, China) and were redistilled in an all-glass system before use. Florisil (60-100 mesh) was purchased from Supelco and was activated in drying oven at $130^{\circ} \mathrm{C}$ for $16 \mathrm{~h}$. Anhydrous sodium sulfate (Beijing Chemical Factory, China) was heated at $600^{\circ} \mathrm{C}$ for $12 \mathrm{~h}$ before use.

\section{Sample Collection}

Sixty-three soil samples were collected from the Beijing area. Thirtythree samples outer the Fourth-ring Road were classified as outskirts soil samples and 30 within the Fourth-ring Road were classified as urban soil samples. The sampling locations covered $1,080 \mathrm{~km}^{2}$ with a relatively uniform distribution using a grid design based on approximately equal longitude and latitude. The study area was divided into regular grids of $4 \times 4 \mathrm{~km}^{2}$, within which the topsoil samples $(5-30 \mathrm{~cm})$ were collected. Each of the composite soil samples was made of 16 sub-samples obtained in a $1 \times 1 \mathrm{~km}^{2}$ grid using an acid-cleaned stainless steel hand auger. The detailed sampling locations are shown in Figure 1. The soil was air-dried at room temperature, thoroughly mixed, sieved to 30 mesh, and transferred to pre-cleaned amber glass, and was maintained at $-4^{\circ} \mathrm{C}$ until further processing. The remaining water content in the soil was determined gravimetrically after drying individual composite soil sample in an oven at $105^{\circ} \mathrm{C}$ for $12 \mathrm{~h}$. All the results were reported as dried weight.

\section{Extraction and Cleanup}

Five grams of soil was ground with anhydrous sodium sulfate into free flowing powder. The sample was ultrasonically extracted in centrifuge tube with $30 \mathrm{~mL}$ of $1 / 1(\mathrm{v} / \mathrm{v})$ acetone/hexane for $5 \mathrm{~min}$ and then the extract was separated by centrifugation. The process was repeated for three times. The solvents were combined and were evaporated by rotary evaporator with a reduce pressure at $35^{\circ} \mathrm{C}$ water bathing; then hexane was added as solvent. The concentrated extract was transferred to a chromatograph column $(30 \mathrm{~cm} \times 10 \mathrm{~mm}$ I.D. $)$ containing $5 \mathrm{~g}$ activated Florisil and $1 \mathrm{~g}$ of anhydrous sodium sulfate on the column top. The Florisil was soaked in hexane and was filled in the column. The concentrated extract was transferred to the column top and was eluted by $50 \mathrm{~mL} \mathrm{n}$-hexane/diethyl-ether (9/1). The washing solvent was evaporated by rotary evaporator, then was adjusted to $0.2 \mathrm{~mL}$ for $\mathrm{GC}$ analysis.

\section{Chromatographic Analysis}

The identification and quantification of organochlorine pesticides were carried out with an Agilent 6890 gas chromatograph equipped with micro-cell ${ }^{63} \mathrm{Ni}$ electron capture detector $(\mu$-ECD). The separation was performed on a fused silica capillary column (HP-5, $30 \mathrm{~m} \times$ $0.25 \mathrm{~mm}$ I.D., and $0.25-\mu \mathrm{m}$ film thickness). The carrier gas was nitrogen with a flow of $0.7 \mathrm{~mL} \mathrm{~min}^{-1}$. The injector and detector temperature were $225^{\circ}$ and $310^{\circ} \mathrm{C}$, respectively. The $\mathrm{GC}$ oven temperature was programmed as followed: initial temperature $100^{\circ} \mathrm{C}$ held for $2 \mathrm{~min}$, increased to $160^{\circ} \mathrm{C}$ at a rate of $10^{\circ} \mathrm{C} \mathrm{min}{ }^{-1}$, then increased to $230^{\circ} \mathrm{C}$ at a rate of $4^{\circ} \mathrm{C} \mathrm{min}{ }^{-1}$, followed by $10^{\circ} \mathrm{C} \mathrm{min}{ }^{-1}$ ascent to $280^{\circ} \mathrm{C}$, maintained for $10 \mathrm{~min}$. Then, $1 \mu \mathrm{L}$ of sample was injected in splitless mode. Peak identification of organochlorine pesticide was made by comparison of retention times with corresponding standards.

\section{Physic-Chemicals Property Analysis}

The $\mathrm{pH}$ was estimated by dissolving soil mineral material in distilled water in terms of the ratio of 1:2.5 (soil/water) using an Orion Reserch Model $501 \mathrm{pH}$ meter. Organic matter content was analyzed by combustion after acidification to remove carbonates using the WalkleyBlack method (Nelson and Sommers 1982). Particle size distribution was determined by the pipette method and classification of the soil texture was based on Soil Survey Division Staff (1993).

\section{Quality Control}

Quality control was based on the following procedures. Method blanks were first run. The matrix blanks, the recoveries of OCPs, and the limits of detection (LODs) were based on the measures of deep layer soil from the rural area of Beijing, which had little interference for the target analytes. The average recovery experiments in triple were done by spiked known concentration standards in matrix blank soil and were $87 \pm 7 \%$ for DDTs and $82 \pm 4 \%$ for HCHs. Before extraction, each of the soil samples was spiked with known amounts of TCMX as surrogate to compensate for the losses of compounds Recoveries for TCMX surrogate were $72-108 \%$ (mean 85\%) and the values were satisfactory so that no correction was applied to the 
Table 1. Concentrations of organochlorine pesticides $\left(\mathrm{ng} \mathrm{g}^{-1}\right)$ and selected soil properties in soils of Beijing

\begin{tabular}{|c|c|c|c|c|c|c|}
\hline & Minimum & Maximum & Median & Geometric mean & Mean & Std. deviation \\
\hline$\alpha-\mathrm{HCH}$ & nd & 3.90 & 0.56 & 0.52 & 0.88 & 0.93 \\
\hline$\beta-\mathrm{HCH}$ & 0.37 & 44.74 & 2.34 & 2.86 & 4.99 & 7.32 \\
\hline$\gamma-\mathrm{HCH}$ & nd & 12.86 & 1.01 & 1.10 & 1.96 & 2.57 \\
\hline$\delta-\mathrm{HCH}$ & nd & 4.88 & 0.36 & 0.38 & 0.75 & 0.94 \\
\hline $\mathrm{p}, \mathrm{p}^{\prime}-\mathrm{DDE}$ & 0.22 & 832.37 & 21.38 & 16.44 & 40.79 & 105.19 \\
\hline $\mathrm{p}, \mathrm{p}^{\prime}-\mathrm{DDD}$ & 0.15 & 206.88 & 1.28 & 1.81 & 8.42 & 27.17 \\
\hline $\mathrm{o}, \mathrm{p}^{\prime}-\mathrm{DDT}$ & nd & 146.94 & 4.91 & 4.85 & 14.02 & 22.33 \\
\hline $\mathrm{p} ; \mathrm{p}^{\prime}-\mathrm{DDT}$ & nd & 1924.76 & 8.72 & 5.92 & 46.50 & 241.78 \\
\hline$\Sigma$ DDTs & 0.77 & 2178.56 & 43.42 & 38.21 & 109.73 & 291.66 \\
\hline$\Sigma \mathrm{HCHs}$ & 1.36 & 48.83 & 4.50 & 5.78 & 8.57 & 9.55 \\
\hline Total C (g/kg) & 3.80 & 28.65 & 16.42 & 15.09 & 15.92 & 4.84 \\
\hline $\mathrm{pH}(1: 2.5)$ & 7.98 & 8.91 & 8.35 & 8.38 & 8.38 & 0.15 \\
\hline Sand $(\%)$ & 20.63 & 65.45 & 44.95 & 42.61 & 44.58 & 12.80 \\
\hline Silt $(\%)$ & 27.70 & 61.55 & 43.95 & 43.07 & 44.17 & 9.74 \\
\hline Clay $(\%)$ & 6.80 & 22.33 & 11.03 & 11.04 & 11.56 & 3.66 \\
\hline
\end{tabular}

samples. The limits of detection (LODs) as three times response of signal-to-noise in matrix blank sample ranged from $0.05 \mathrm{ng} \mathrm{g}^{-1}$ for $\alpha$ -

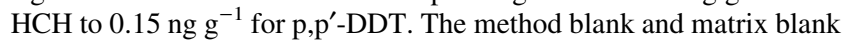
were measured for duplicate with each batch of 10 samples. All data have been blank corrected.

\section{Data Process}

Correlation analysis and $t$-test were carried out using SPSS 11.5 statistical software, while the contour maps were preformed using Surfer 8.0.

\section{Results and Discussion}

\section{Contamination Level of HCHs and DDTs in Soil From Beijing HCHs}

All the samples presented the residues of $\mathrm{HCHs}$ (see Table 1). Total HCHs content (equivalent sum of $\alpha-+\beta-+\gamma-+\delta-\mathrm{HCH}$ ) ranged from 1.36 to $48.83 \mathrm{ng} \mathrm{g}^{-1}$ with $5.78 \mathrm{ng} \mathrm{g}^{-1}$ as geometric mean. The highest concentration was found in site 33 $\left(48.83 \mathrm{ng} \mathrm{g}^{-1}\right)$ and site $19\left(45.81 \mathrm{ng} \mathrm{g}^{-1}\right)$. Such a concentration was higher than the residual levels in pristine areas such as the Tibet plateau in China (HCHs: $0.18-5.38 \mathrm{ng} \mathrm{g}^{-1}$; Fu et al. 2001) and in soil from the exurb of Beijing such as Guanting Reservoir (ND-19.23 $\mathrm{ng} \mathrm{g}^{-1}$, Hong et al. 2004). This may be attributed to the effect of more densely anthropogenic activities resulting in the relatively higher level of $\mathrm{HCHs}$ in the study area than those in Tibet and Guanting Reservoir. However, $\mathrm{HCHs}$ content was lower than that in the agricultural soil of the greenhouse from Beijing outskirts $\left(15.77 \pm 6.0 \mathrm{ng} \mathrm{g}^{-1}\right.$; Ma et al. 2003) and was nearly one order of magnitude lower than that in agricultural soil from the northwestern suburb of Beijing (32.0 ng g ${ }^{-1}$, Shi et al. 2005). This result could be attributed to the application of $\mathrm{HCHs}$ mainly for improving the agricultural production over a long period of time. When compared with recent data of $\mathrm{HCHs}$ from Tianjin, which is a city adjacent to Beijing, the level of $\mathrm{HCHs}$ in this study was 1-3 orders of magnitude lower than that in the outskirts sewage-irrigated soil (368.5-4689.1 $\mathrm{ng} \mathrm{g}^{-1}$, Gong et al. 2002) and that in the whole region soil (45.8 $\mathrm{ng} \mathrm{g}^{-1}$, Gong et al. 2004b), which could account for the fact that $\mathrm{HCH}$ is still produced in Tianjin in China today. Compared with the other areas abroad, the value of concentration was lower than those in various soils in Romania (rural area: $28.4 \pm 33.7 \mathrm{ng} \mathrm{g}^{-1}$; urban area: $29.2 \pm 27.1 \mathrm{ng} \mathrm{g}^{-1}$; Covaci et al. 2001) and was much lower than agricultural soil in India $\left(0.42-86000 \mathrm{ng} \mathrm{g}^{-1}\right.$; Kawano et al. 1992). HCHs content in the soil of Beijing was comparable to that in the soils from the southern part of Poland $\left(11 \pm 29 \mathrm{ng} \mathrm{g}^{-1}\right.$ in Kraków and $6 \pm 3 \mathrm{ng} \mathrm{g}^{-1}$ in Katowice; Falandysz et al. 2001) and that in the agricultural soil from central Germany (5.22-11.50 $\mathrm{ng} \mathrm{g}^{-1}$, Manz et al. 2001). However, it was higher than that in some European countries (Belgium, Italy, and Greece) (Covaci et al. 2002) and that in urban soil in India (park soil: $0.6-3.6 \mathrm{ng} \mathrm{g}^{-1}$; roadside: $0.55-$ $27 \mathrm{ng} \mathrm{g}^{-1}$; Kawano et al. 1992), and that in tropical soils in Giza of Egypt (nd-16.2 $\mathrm{ng} \mathrm{g}^{-1}$, Kabbany et al. 2000).

In terms of the distribution of individual $\mathrm{HCH}$ isomers, the residue of $\beta-\mathrm{HCH}$ was the highest among the four $\mathrm{HCH}$ isomers (from 0.37 to $44.74 \mathrm{ng} \mathrm{g}^{-1}$ ) and accounted for $53 \%$ of the total HCHs. The residue of $\gamma-\mathrm{HCH}$ was the second highest among the four $\mathrm{HCH}$ isomers (ND-12.86 $\mathrm{ng} \mathrm{g}^{-1}$ ) and accounted for $23 \%$ of the $\Sigma$ HCHs. The other two isomers, $\alpha$ $\mathrm{HCH}$ and $\delta-\mathrm{HCH}$, had similar concentration levels (mean concentrations of 0.88 and $0.75 \mathrm{ng} \mathrm{g}^{-1}$, respectively). Due to the fraction of $\beta-\mathrm{HCH}$ in technical $\mathrm{HCHs}$ that ranged from 5 to $14 \%$ (Qiu et al. 2004), a high percent ratio of $\beta-\mathrm{HCH}$ in this study meant that there was a lack of new $\mathrm{HCH}$ sources in the research area. Furthermore, because the ratio of $\alpha-/ \gamma-\mathrm{HCH}$ is relatively stable in technical $\mathrm{HCH}, \alpha-\gamma-\mathrm{HCH}$ has been used to monitor the source and use history of HCHs (Kim et al. 2002). The ratio of $\alpha-\gamma-\mathrm{HCH}$ would be in the range of 4.64-5.83 for the technical HCHs and nearly zero for lindane (Zhang et al. 2004). In this study, almost all of the $\alpha-\gamma-\gamma \mathrm{HCH}$ ratios were less than 0.8 and ratios between 1 and 2 were only observed in nine of 63 samples. The ratio was much lower than that of the technical $\mathrm{HCH}$, which indicates that a long time has elapsed since the use of technical HCHs in the area and/or implies the presence of a possible emission source of lindane. This result about the HCH source was consistent with other reports on HCHs, which indicated that the use of lindane had occured in human milk, pine needles, and PM2.5/PM10 in Beijing ( $\mathrm{Yu}$ et al. 2003; Xu et al. 2004, 2005). The high concentration of HCHs in site $33\left(48.83 \mathrm{ng} \mathrm{g}^{-1}\right)$ might contribute to the fact that 
some pesticide and chemical industry factories had never been located in the areas in the past. The high concentration of HCHs in site 19 (45.81 $\mathrm{ng} \mathrm{g}^{-1}$ ) might indicate that a larger amount of HCHs had been used previously in this site for the yield of agricultural product.

\section{DDTS}

Residues of DDTs were all detected in soils from Beijing (see Table 1). The $\Sigma$ DDT (equivalent sum of p, $\mathrm{p}^{\prime}$-DDE, p, $\mathrm{p}^{\prime}-\mathrm{DDD}$, $\mathrm{o}, \mathrm{p}^{\prime}$-DDT, and $\mathrm{p}, \mathrm{p}^{\prime}$-DDT) content ranged from 0.77-2178.56 $\mathrm{ng} \mathrm{g}^{-1}$ with $38.2 \mathrm{ng} \mathrm{g}^{-1}$ as a geometric mean. In comparison with residual levels in pristine areas such as the Tibet plateau in China (DDTs: n.d.-2.83 ng/g, Fu et al. 2001), the level of DDTs in the study area was considerably higher. Furthermore, it was also higher than that in soil around the Guanting Reservoir located in the exurb of Beijing (ND-176.01 $\mathrm{ng} \mathrm{g}^{-1}$, Hong et al. 2004). However, the content (the geometric mean was used in order to exclude the effect of too high concentration in this study) was lower than those in the greenhouse soils from the Beijing suburbs $\left(64.44 \pm 30.36 \mathrm{ng} \mathrm{g}^{-1}\right.$; Ma et al. 2003) and in agricultural soil from the northwestern suburb of Beijing (381.3 $\mathrm{ng} \mathrm{g}^{-1}$ for DDTs; Shi et al. 2005). It seemed that the difference of residual level of DDTs between the study area and the areas mentioned above were probably related to the effect of anthropogenic factors and agricultural application. Less anthropogenic activities and less agricultural product could cause less DDTs residues. It was noted that the level of DDTs in this study was comparable to that in Tianjin area (one of the largest cities in northern China) $\left(49.6 \pm 126.8 \mathrm{ng} \mathrm{g}^{-1}\right.$, Gong et al. 2004a). Due of the known continuous production and application of DDTs in Tianjin until now (with an annual production of 2500-3500 tons DDT, Hu and Liu 2003), this comparison probably indicated that some application of DDTs existed in Beijing. Compared with some oversea areas, DDT content in the soil of Beijing was higher than that in the urban soil from India (park soil: $3.4-90 \mathrm{ng} \mathrm{g}^{-1}$; roadside: 16-190 $\mathrm{ng} \mathrm{g}^{-1}$; Kawano et al. 1992), and that in agriculture soils in Giza of Egypt (nd, Kabbany et al. 2000) and those in soils from Belgium, Italy, and Greece (Covaci et al. 2002). However, it (geometric mean was used) was lower than that in Romanian soil $\left(226.9 \pm 157.2 \mathrm{ng} \mathrm{g}^{-1}\right.$ for rural soil and $113.1 \pm 151.8 \mathrm{ng} \mathrm{g}^{-1}$ for urban soil; Covaci et al. 2001) and that in the agricultural and garden soils in the US Corn Belt (ND-11800 $\mathrm{ng} \mathrm{g}^{-1}$, Aigner et al. 1998) as well as that in soil in Poland $\left(110 \pm 89 \mathrm{ng} \mathrm{g}^{-1}\right.$ in Kraków and $260 \pm 620 \mathrm{ng} \mathrm{g}^{-1}$ in Katowice, Falandysz et al. 2001).

As far as DDT and its metabolites are concerned, the concentrations were in general in this order: $\mathrm{p}, \mathrm{p}^{\prime}$-DDE $>\mathrm{p}, \mathrm{p}^{\prime}$-DDT $>$ o, $\mathrm{p}^{\prime}$-DDT > p, $\mathrm{p}^{\prime}$-DDD. $\mathrm{p}, \mathrm{p}^{\prime}$-DDT and $\mathrm{p}, \mathrm{p}^{\prime}$-DDE were the major contaminants with geometric mean concentrations of 5.92 and $16.44 \mathrm{ng} \mathrm{g}^{-1}$ dry weight, respectively. The geometric mean concentrations of $\mathrm{p}, \mathrm{p}^{\prime}$-DDD and $\mathrm{o}, \mathrm{p}^{\prime}$-DDT were 1.81 and $4.85 \mathrm{ng} \mathrm{g}^{-1}$ dry weight, respectively. The concentration of p, $\mathrm{p}^{\prime}$-DDE in 51 of 63 samples was higher than that of $p, p^{\prime}-$ DDT. It seems the higher concentration of DDE found in the Beijing area was probably related to the longer persistence of DDE than those of DDD and the parent compound DDT (Aguillar 1984). In addition, because DDT is reductively de-chlorinated to DDD under anaerobic conditions and to DDE under aerobic conditions (Heberer and Dünnbier 1999; Fellenberg 2000), this result was consistent with the fact that surface soil tends to be aerobic probably resulted in the low percentage of DDD and the high percentage of DDE among the metabolites of DDT in the study areas.

Since the level of DDT in the natural environment will decrease with time and the major metabolite is expected to be DDE and DDD, the ratio of (p, $\left.\mathrm{p}^{\prime}-\mathrm{DDE}+\mathrm{p}, \mathrm{p}^{\prime}-\mathrm{DDD}\right) / \mathrm{p}, \mathrm{p}^{\prime}-\mathrm{DDT}$ may be used as an indicator of resident time of $\mathrm{p}, \mathrm{p}^{\prime}$-DDT in the environment (Qiu et al. 2004). The ratio $>1$ is normally expected for aged mixtures in the environment and $<1$ indicated the relatively recent exposure to parent DDT (Jaga and Dharmani 2003). In this study, the ratio of ( $p, p^{\prime}-D D E+p, p^{\prime}$ DDD)/p, $\mathrm{p}^{\prime}$-DDT was $>1$ in nearly all samples and the ratios in only two soil samples (site 22 and site 36$)$ were $<1(0.1$ and 0.3 , respectively). The predominance of metabolites indicated extensive contamination of DDT occurred in the past. However, the concentration of $\mathrm{p}, \mathrm{p}^{\prime}$-DDT in some sites was abnormally high(such as site 22:1924.76 $\mathrm{ng} \mathrm{g}^{-1}$ ) and this might indicate that there seemed to be some recent input of DDT here. At the same time, Site 4 had a high concentration of DDE (832.37 $\mathrm{ng} \mathrm{g}^{-1}$ ), probably indicating that large amounts of DDTs had been used in this site in the past. Since sites 4 and 22 are located in the outskirts of Beijing, they should be paid close attention for agricultural application.

Recently, o, $\mathrm{p}^{\prime}$-DDT/p,p'-DDT was used to distinguish the DDT pollution caused by technical DDT from that by technical dicofol, which was defined as a "dicofol type DDT pollution" (Qiu et al. 2005). Since o, p'-DDT is more unstable than p, $\mathrm{p}^{\prime}$-DDT in the environment (Martijn et al. 1993), it was impossible that the ratio of $o, p^{\prime}-D D T / p, p^{\prime}-D D T$ was higher than that of technical DDT, whereas the characteristic of "dicofol type DDT pollution" was with a higher o, $\mathrm{p}^{\prime}$-DDT/ $\mathrm{p}, \mathrm{p}^{\prime}$-DDT ratio than of technical DDT. Generally, o, $\mathrm{p}^{\prime}$-DDT/ $\mathrm{p}, \mathrm{p}^{\prime}$-DDT ranged from $0.2-0.3$ in technical DDT and from 1.3-9.3 or higher in technical dicofol (Qiu et al. 2005). In this study, the ratio of $o, p^{\prime}-D D T / p, p^{\prime}$-DDT ranged from 0.01 to 16 except site 5 and site 9 with no detected p,p'-DDT. DDTs in 20 samples with the ratio $<0.3$ showed the source of technical DDT, and in 14 samples with the ratio $>1.3$ indicated the attribution of technical dicofol. The value in 20 samples with ratio $<0.3$ showed that source of technical DDT, and that in 14 samples with the ratio $>1.3$ indicated the attribution of technincal dicofol, and that in 29 samples with the ratio $<1.3$ and $<0.3$, suggested the mixed pollution source of technical DDT and technical dicofol. As a result, DDTs pollution in the surface soil of Beijing not only came from the residue of technical DDT in the environment but also from the input of dicofol impurity. This result about the source of DDT agreed with previous reports which indicated that technical DDTs or impure dicofol had been released in human milk, pine needle, and pm2.5/pm10 in Beijing (Yu et al. 2003; Xu et al. 2004, 2005).

\section{Temporal and Spatial Distribution of HCHs and DDTs}

A survey of the level of HCHs and DDTs contamination in soil in the entire region of Beijing only was done in 1977-1980 
Table 2. The temporal changes of HCHs and DDTs in soils from Beijing

\begin{tabular}{|c|c|c|c|c|c|}
\hline \multirow[b]{2}{*}{ Type of soil } & \multirow[b]{2}{*}{ Sampling time } & \multicolumn{2}{|c|}{ HCHs $\left(\right.$ ngg $\left.^{-1}\right)$} & \multicolumn{2}{|l|}{ DDTs $\left(\right.$ ngg $\left.^{-1}\right)$} \\
\hline & & Mean & Range & Mean & Range \\
\hline Orchard soil & 1977 & $250 \pm 360$ & $30-1900$ & $110 \pm 990$ & $50-4,700$ \\
\hline Orchard soil & 1978 & $200 \pm 170$ & $35-580$ & $2000 \pm 2,500$ & $14-6,700$ \\
\hline Cornfield & 1977 & 5,700 & $200-6200$ & 480 & $43-1,100$ \\
\hline Cornfield & 1978 & 460 & $64-5,800$ & 810 & $60-6,500$ \\
\hline Soil not used by OCPs & 1980 & $130 \pm 150$ & $15-4,800$ & $390 \pm 1,300$ & ND-5,000 \\
\hline Soil from this study & 2003 & $8.6 \pm 9.6$ & $1.4-48.8$ & $110 \pm 291$ & $0.8-2,178.6$ \\
\hline
\end{tabular}
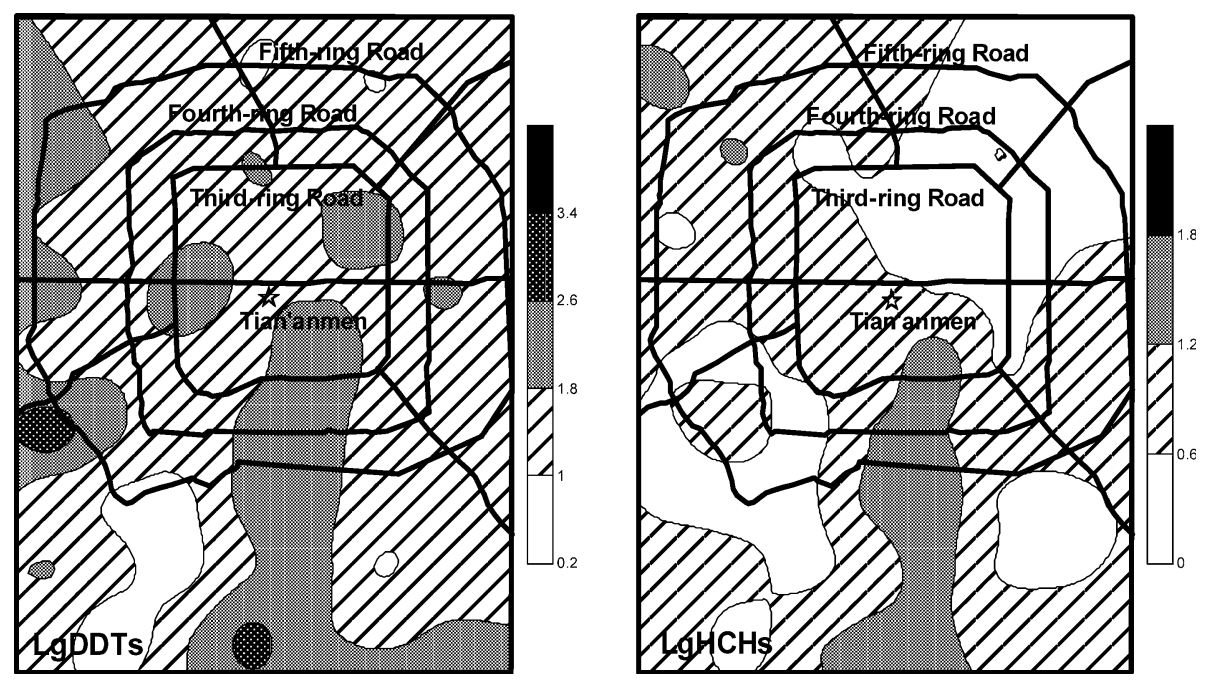

Fig. 2. The spatial distribution of HCHs and DDTs

(excluding the four old urban regions). The results presented in Table 2 indicate some differences in the levels of HCHs and DDTs in Beijing soil 20 years ago (Beijing EPB 1982, unpublished data) in the present study. In comparison to soils collected from the regions without the use of OCPs in 1980, the mean of the HCHs decreased from 130 to $8.6 \mathrm{ng} \mathrm{g}^{-1}$ and 93\% was degraded and the mean of DDTs was reduced from 390 to $110 \mathrm{ng} \mathrm{g}^{-1}$ and $72 \%$ was degraded. In general, it can be seen that the residues of HCHs and DDTs used 20 years ago had a great effect on their residual levels in the soil now.

The spatial distribution of HCHs and DDTs content (log transformation was done in order to decrease the difference from the data) are shown in Figure 2 by a counter plot. As for HCHs and DDTs, the maps indicat that some communal areas in the south of Beijing existed with relatively higher concentrations, and some areas in the north and the east of Beijing existed with relatively lower levels. The land type in the south suburb of Beijing is mainly for agriculture application (e.g., crops and vegetable) so that large amounts of OCPs had even been used for the yield of produce. Additionally, due to the lack of water resources in Beijing, soil in the southeast of Beijing was even irrigated by wastewater for a long time. As a result, the effects of OCPs in the south suburb were higher than in the north and east areas. Additionally, the other areas with the higher content of $\mathrm{HCHs}$ were distributed in the northwest of Beijing and those with the higher content of DDTs were distributed in the west suburb and urban area of Beijing. It was estimated that approximately 500 tons of OCPs were sold annually in the western suburbs of Beijing and 260 tons were sold in the eastern suburbs from 1972 to 1974, which probably explains the higher levels of OCPs in the west suburbs of Beijing (Cooperation Group 1980). This result agrees well with the high level of OCPs detected in agricultural soil from the northwestern suburb of Beijing, which was surveyed in 2003 (2.0-760.3 $\mathrm{ng} \mathrm{g}^{-1}$ for $\mathrm{HCH}$ and 7.2-2910 $\mathrm{ng} \mathrm{g}^{-1}$ for DDT, Shi et al. 2005). A higher value of DDTs in the urban area probably attributed to the intensity of its usage for activities such as delousing household pets and bed linen.

Due to the different application types of soil between the urban and outskirts areas, a different spatial distribution and source of OCPs may result. The concentration values of $\mathrm{HCHs}$ were similar between the urban area and outskirts with a geometric mean of $5.3 \mathrm{ng} \mathrm{g}^{-1}$ and $6.2 \mathrm{ng} \mathrm{g}^{-1}$, respectively. The geometric mean of DDTs in the urban area and outskirts was $50.5 \mathrm{ng} \mathrm{g}^{-1}$ and $29.7 \mathrm{ng} \mathrm{g}^{-1}$, respectively. $t$-test of OCPs between the urban and outskirts areas of Beijing showed that both of the concentrations of o,p-DDT and p,p-DDT in the urban area were significantly higher than those identified for the outskirts area, while those of $\alpha-\mathrm{HCH}$ and p,p-DDD in the urban area were significantly lower than those in the outskirts area (see Table 3). The predominance of parent DDTs in urban area probably reflected a larger amount of usage or a more recent release of DDTs for pest and vector control in the urban region, while the predominance of $\alpha-\mathrm{HCH}$ in the outskirts probably 
Table 3. Geometric mean and $t$-test of OCPs using log-transformed concentrations between the urban area and outskirts areas (ng $\mathrm{g}^{-1}$, dry weight)

\begin{tabular}{|c|c|c|c|c|c|c|c|c|c|c|}
\hline & $\alpha-\mathrm{HCH}$ & $\beta-\mathrm{HCH}$ & $\gamma-\mathrm{HCH}$ & $\delta-\mathrm{HCH}$ & $\mathrm{pp}^{\prime}-\mathrm{DDE}$ & $\mathrm{pp}^{\prime}-\mathrm{DDD}$ & $\mathrm{op}^{\prime}$-DOT & $\mathrm{pp}^{\prime}$-DDT & $\Sigma \mathrm{DDT}$ & $\Sigma \mathrm{HCH}$ \\
\hline Geometric mean Outskirts $(\mathrm{n}=33)$ & 0.9 & 2.7 & 1.2 & 0.4 & 12.1 & 4.1 & 2.7 & 2.8 & 29.7 & 6.2 \\
\hline Urban $(\mathrm{n}=30) t$-test & 0.3 & 3.1 & 1.0 & 0.3 & 23.0 & 0.7 & 9.2 & 13.4 & 50.5 & 5.3 \\
\hline$t$ & 3.575 & -0.645 & 0.364 & 0.837 & -1.901 & 5.338 & -3.096 & -2.832 & -1.535 & 0.676 \\
\hline$p$ value & $0.001 *$ & 0.521 & 0.717 & 0.406 & 0.062 & $0.000 *$ & $0.003 *$ & $0.006^{*}$ & 0.130 & 0.502 \\
\hline
\end{tabular}

*Significant at the 0.05 level.

Table 4. Correlations between OCPs and selected soil properties in soils from Beijing

\begin{tabular}{|c|c|c|c|c|c|c|c|c|c|c|c|c|c|c|c|}
\hline & $\alpha-\mathrm{HCH}$ & $\beta-\mathrm{HCH}$ & $\gamma-\mathrm{HCH}$ & $\delta-\mathrm{HCH}$ & $\mathrm{pp}^{\prime}-\mathrm{DDE}$ & $\mathrm{pp}^{\prime}-\mathrm{DDD}$ & $\mathrm{op}^{\prime}$-DDT & $\mathrm{pp}^{\prime}-\mathrm{DDT}$ & $\Sigma$ DDT & $\Sigma \mathrm{HCH}$ & TOC & PH & Sand & Silt & Clay \\
\hline$\alpha-\mathrm{HCH}$ & $1.00^{* *}$ & & & & & & & & & & & & & & \\
\hline$\beta-\mathrm{HCH}$ & $0.33 * *$ & $1.00 * *$ & & & & & & & & & & & & & \\
\hline$\gamma-\mathrm{HCH}$ & $0.18 * *$ & 0.24 & $1.00 * *$ & & & & & & & & & & & & \\
\hline$\delta-\mathrm{HCH}$ & 0.23 & 0.23 & 0.15 & $1.00 * *$ & & & & & & & & & & & \\
\hline $\mathrm{pp}^{\prime}-\mathrm{DDE}$ & 0.11 & $0.60 * *$ & $0.31 * *$ & 0.09 & 1.00 & & & & & & & & & & \\
\hline $\mathrm{pp}^{\prime}-\mathrm{DDD}$ & $0.50 * *$ & $0.45^{* *}$ & 0.21 & 0.19 & $0.45^{* *}$ & $1.00 * *$ & & & & & & & & & \\
\hline $\mathrm{op}^{\prime}$-DDT & -0.04 & $0.44 * *$ & 0.13 & 0.11 & $0.80 * *$ & $0.33 * *$ & $1.00 * *$ & & & & & & & & \\
\hline $\mathrm{pp}^{\prime}$-DDT & -0.12 & 0.18 & 0.13 & -0.17 & $0.51 * *$ & 0.12 & 0.45 & $1.00 * *$ & & & & & & & \\
\hline$\Sigma \mathrm{DDT}$ & 0.09 & $0.54 * *$ & 0.23 & 0.08 & 0.92 & $0.56^{* *}$ & $0.85^{* *}$ & $0.61 * *$ & $1.00 * *$ & & & & & & \\
\hline$\Sigma \mathrm{HCH}$ & $0.48 * *$ & $0.90 * *$ & $0.46^{* *}$ & $0.35 * *$ & $0.57 * *$ & $0.57 * *$ & $0.38 * *$ & 0.12 & $0.59 * *$ & $1.00 * *$ & & & & & \\
\hline TOC & 0.14 & $0.33 *$ & -0.06 & 0.18 & $0.36 *$ & 0.26 & $0.45^{* *}$ & 0.21 & 0.28 & 0.26 & $1.00 * *$ & & & & \\
\hline $\mathrm{pH}$ & -0.05 & -0.27 & 0.13 & -0.12 & -0.24 & -0.17 & -0.31 & -0.20 & -0.16 & -0.20 & $-0.81 * *$ & $1.00 * *$ & & & \\
\hline Sand & $-0.37 *$ & -0.19 & 0.04 & -0.04 & -0.31 & -0.38 & $-0.35^{*}$ & -0.03 & -0.23 & -0.23 & $-0.65 * *$ & $0.53 * *$ & $1.00 * *$ & & \\
\hline Silt & $0.37 *$ & 0.30 & 0.03 & 0.22 & $0.44 * *$ & 0.39 & $0.42 * *$ & 0.02 & 0.31 & 0.29 & $0.72 * *$ & $-0.55^{* *}$ & $0.91 * *$ & $1.00 *$ & \\
\hline Clay & $0.43 * *$ & 0.21 & -0.02 & 0.05 & $0.35 *$ & 0.41 & $0.34 *$ & 0.23 & 0.23 & 0.25 & $0.67 * *$ & $-0.58 * *$ & $-0.94 * *$ & $0.86^{* *}$ & $1.00 * *$ \\
\hline
\end{tabular}

* Significant at the 0.01 level (2-tailed).

** Significant at the 0.01 level (2-tailed).

suggested a larger amount or longer time of usage of technical $\mathrm{HCH}$ for the yield for agricultural application in the outskirts.

\section{Correlation Analysis}

Soil particles form a fine mesh that filters solid material out of seeping water. Simultaneously, the soil pores function as a storage site for materials. Humus provides for a firmer fixation, with numerous contaminants attached to them. Soil characteristics are thought to have some role in determining the concentrations of pollutants (Fellenberg 2000). For the soils examined in this study, these physic-chemical properties of soil ( $\mathrm{pH}$, total $\mathrm{C}$, and the particle size) were used to analyze any relationship with the DDTs and $\mathrm{HCHs}$ residues (log transformed). It seemed that there was an insignificant correlation between OCPs and soil geochemical variables (see Table 4). In the present study, though the levels of DDTs and HCHs were so different in the soil samples, HCHs and DDTs showed a strong positive correlation $(r=0.59, p<0.01)$. This correlation probably showed that both HCHs and DDTs had similar source/fate in the study area. However, as for DDT, when two sites (4 and 22), which had an abnormally high concentration, were excluded, the correlation between DDTs and TOC was predominant $(r=0.40, p<0.01)$. This probably indicates that a long time elapsed without the usage of DDTs in most areas of Beijing. As for HCHs, factors such as high vapor pressure, high volatility, and high solubility in water may be responsible for the insignificant outcome.

\section{Risk Assessment}

According to the guidelines of Chinese environmental quality standard for soil (GB 15618-1995), the maximum allowable concentration of class I soil was $<50 \mathrm{ng} \mathrm{g}^{-1}$, that of class II soil was $<500 \mathrm{ng} \mathrm{g}^{-1}$, and that of class III soil was $<1,000 \mathrm{ng}$ $\mathrm{g}^{-1}$ for both $\Sigma \mathrm{HCH}$ and $\Sigma$ DDT, respectively. In this study, the levels of $\Sigma \mathrm{HCHs}$ in all the soil samples were beneath the criteria of class I. The levels of $\Sigma$ DDT in 37 samples were beneath the criteria of class I and those in 24 samples were beneath the criteria of class II. However, seriously high concentrations residues of $\Sigma$ DDT were found in sites 22 ( $\Sigma$ DDT $>$ class III) and 4 ( $\Sigma$ DDT $>$ class II). Therefore, there is a potential risk for human health and these sites should be paid close attention to. On the basis of current guide values and limits for soil in the Dutch List (Manz et al. 2001), the concentration of DDTs in only two samples was less than the reference value $\left(2.50 \mathrm{ng} \mathrm{g}^{-1}\right)$ and that of $\gamma-\mathrm{HCH}$ in only one sample was less than the reference value $\left(0.05 \mathrm{ng}^{-1}\right)$. However, the contents in all the samples collected did not exceed the intervention values of soil for DDX $(4,000 \mu \mathrm{g}$ $\left.\mathrm{kg}^{-1}\right)$ and HCHs $\left(2,000 \mu \mathrm{g} \mathrm{kg}^{-1}\right)$ in the Dutch List.

\section{Conclusions}

The levels of DDTs and HCHs contamination were surveyed in the present study in the soil from Beijing. The contour map indicated that the region with a high level of OCPs distribution 
was mainly concentrated in the west and south suburbs and urban areas of Beijing city. Risk assessment and comparison with other reports indicated contamination of OCPs were not too severe in the Beijing region. DDTs should be paid closer attention to due to their level being 10-fold higher than HCHs. The source of OCPs in the region of Beijing came mainly from the historical usage of technical $\mathrm{HCH}$ and technical DDT with the input of lindane and impurity of dicofol in some sites. The reasons that cause the high level of $\mathrm{HCHs}$ in sites 33 and 19 and the high level of DDTs in sites 22 and 4 need be explored further. The impurity of dicofol, as a possible new source of DDT pollution in Beijing, is worth focusing on. The results provide important information on the current contamination status of soil in Beijing City, and may help in the development of strategies to be used in monitoring organic pollutants in this region.

Acknowledgments. We acknowledge financial support of this work by State Science and Technology Council Program "973" of the People's Republic of China and Agilent Technologies Co. Ltd (China) for GC-MS analysis. We also thank Xingzhong Li and Daren Zhang for providing data during the course of 1977-1980.

\section{References}

Aguillar A (1984) Relationship of DDE/DDT in marine mammals to the chronology of DDT input to the ecosystem. Can J Fish Aquat Sci 41:840-844

Aigner EJ, Leone AD, Falconer RL (1998) Concentrations and enantiomeric ratios of organochlorine pesticides in soils from the US corn belt. Environ Sci Technol 32:1162-1168

Cai DJ, Sun LJ, Ke JL, Tang GC (1992) Pesticide usage in China. Prepared for Environment Canada Downsview, Ontario, Canada

Cooperation group, 1980. Studies on pollution investigation and prevention measures in Beijing southeast suburbs [Collection] (1976-1979)

Covaci A, Hura C, Schepens P (2001) Selected persistent organochlorine pollutants in Romania. Sci Total Environ 280:143152

Covaci A, Manirakiza P, Schepens P (2002) Persistent Organochlorine Pollutants in Soils from Belgium, Italy, Greece, and Romania. Bull Environ Contam Toxicol 68:97-103

Falandysz J, Brudnowska B, Kawano M, Wakimoto T (2001) Polychlorinated biphenyls and organochlorine pesticides in soils from the southern part of Poland. Arch Environ Contam Toxicol 40:173-178

Fellenberg G (2000) The chemistry of pollution. John Wiley \& Sons, Chichester, pp 113-127

Finizion A, Bidleman TF, Szeto SY (1998) Emission of chiral pesticides from an agricultural soil in the fraser valley, British Columbia. Chemosphere 36:345-355

Fu J, Mai B, Sheng G, Zhang G, Wang X, Peng P, Xiao X, Ran R, Cheng F, Peng X, Wang Z, Tang UW (2003) Persistent organic pollutants in environment of the Pearl River Delta, China: an overview. Chemosphere 52:1411-1422

Fu S, Chu SG, Xu XB (2001) Organochlorine pesticide residue in soils from Tibet, China. Bull Environ Contam Toxicol 66:171-177

Gong ZM, Zhu X, Cui Y, Xu F, Li B, Chao J, Tao S, Shen W, Zhao X, Han L (2002) Local spatial variation of organochlorine pesticides in agricultural soils from Tianjin. City Environ Ecol 15:4-6 (in Chinese)
Gong ZM, Tao S, Xu FL, Dawson R, Liu WX, Cui YH, Cao J, Wang XJ, Shen WR, Zhang WJ, Qing BP, Sun R (2004a) Level and distribution of DDT in surface soils from Tianjin, China. Chemosphere 54:1247-1253

Gong ZM, Xu FL, Dawson R, Cao J, Liu WX, Li BG, Shen WR, Zhang WJ, Qing BP, Sun R (2004b) Residues of hexachlorocyclohexane isomers and their distribution characteristics in soils in the Tianjin area, China. Arch Environ Contam Toxicol 46:432-437

Haugen JE, Wania F, Ritter N, Schlabach M (1998) Hexachlorocyclohexanes in air in southern Norway: Temporal variation, source allocation, and temperature dependence. Environ Sci Technol 32:217-224

Heberer T, Dünnbier U (1999) DDT metabolite bis(chlorophenyl)acetic acid: the neglected environmental contaminant. Environ Sci Technol 33:2346-2351

Hong Z, Yonglong L, Tieyu W, Yajuan S (2004) Accumulation features of organochlorine pesticides residues in soils around Beijing Guanting Reservoir. Bull Environ Contam Toxicol 72:954-961

Hu J, Liu J (2003) Primary assessment report on pesticide POPs in China, Report to GEF

Jaga K, Dharmani C (2003) Global surveillance of DDT and DDE levels in human tissues. Int J Occup Med Environ Health 16:7-20

Jones KC, Voogt P. de (1999) Persistent organic pollutants (POPs): state of the science. Environ Pollut 100:209-221

Kabbany SE, Rashed MM, Zayed MA (2000) Monitoring of the pesticide levels in some water supplies and agricultural land in ElHaram, Giza. J Hazard Mater (A) 72:11-21

Kannan K, Tanabe S, Tatsukawa R (1995) Geographical distribution and accumulation features of organochlorine residues in fish of tropical Asia and Oceania. Environ Sci Technol 29:26732683

Kawano M, Ramesh A, Thao VD, Tatsukawa R (1992) Persistent organochlorine insecticide residues in some paddy, upland and urban soils of India. Int J Anal Chem 48:163-174

Kim SK, Oh JR, Shim WJ, Lee DH, Yim UH, Hong SH, Shin YB, Lee DS (2002) Geographical distribution and accumulation features of organochlorine residues in bivalves from coastal areas of South Korea. Mar Pollut Bull 45:268-279

Li YF, Cai DJ, Singh A (1998) Hexachlorocyclohexane use trends in China and their impact on the environment. Arch Environ Contam Toxicol 35:688-697

Li YF, Cai DG, Shan ZJ, Zhu ZL (2001) Gridded usage inventories of technical hexachlorocyclohexane and lindane for China with $1 / 6^{\circ}$ latitude by $1 / 4^{\circ}$ longitude resolution. Arch Environ Contam Toxicol 41:261-266

Ma LL, Chu SG, Xu XB (2003) Organic contamination in the greenhouse soils from Beijing suburbs, China. J Environ Monit 5:786-790

Manz M, Wenzel KD, Dietze U, Schüürmann G (2001) Persistent organic pollutants in agricultural soils of central Germany. Sci Total Environ 277:187-198

Martijn A, Bakker H, Schreuder RH (1993) Soil persistence of DDT, dieldrin, and lindane over a long period. Bull Environ Contam Toxicol 51:178-184

Nelson DW, Sommers LE (1982) Total carbon, organic carbon, and organic matter. In: Page AL, Miller RH, Keeney DR, (eds) Methods of soil analysis. Part II. 2nd ed. American Society of Agronomy, Madison, WI, pp 539-580

Qiu X, Zhu T, Li J, Pan H, Li Q, Miao G, Gong J (2004) Organochlorine pesticides in the air around the Taihu Lake, China. Environ Sci Technol 38:1368-1374

Qiu X, Zhu T, Yao B, Hu J, Hu S (2005) Contribution of Dicofol to the current DDT pollution in China. Environ Sci Technol 39:4385-4390

Shi Y, Meng F, Guo F, Lu Y, Wang T, Zhang H (2005) Residues of organic chlorinated pesticides in agricultural soils of Beijing, China. Arch Environ Contam Toxicol 49:37-44 
Soil Survey Division Staff (1993) Soil survey manual, revised edition. Agriculture Handbook, vol. 18. United States Department of Agriculture, Washington, DC

Waite DT, Grover R, Westcott ND, Irvine DG, Kerr LA, Sommerstad H (1995) Atmospheric deposition of pesticides in a small southern Saskatchewan watershed. Environ Toxicol Chem 14:117-1175

Wu SP, Cao J, Li BG, Xu FL, Shen WR, Han BP, Sun R, Tao S (2003) Residues and distribution of organochlorine pesticides in airborne particles of different sizes from urban areas. Res Environ Sci 16:36-39

Xu D, Dan M, Song Y, Chai Z, Zhuang G (2005) Concentration characteristics of extractable organohalogens in PM2.5 and PM10 in Beijing, China. Atmosph Environ 39:41194128

Xu D, Deng L, Chai Z, Mao X (2004) Organohalogenated compounds in pine needles from Beijing city, China. Chemosphere 57:13431353

Yu H, Zhu Z, Zhao X, Zhang X, Wang D (2003) Levels of organochlorine pesticides in Beijing human milk 1998. Bull Environ Contam Toxicol 70:193-197

Zhang ZL, Huang J, Yu G, Hong HS (2004) Occurrence of PAHs, PCBs and organochlorine pesticides in Tonghui River of Beijing, China. Environ Pollut 130:249-261

Zhao L, Ma YJ (2001) Analysis of organochlorine pesticides in agricultural environment. Dev Agric Environ 67:37-39 (in Chinese) 